\title{
The effect of intensive grazing systems on the rising plate meter calibration for perennial ryegrass pastures
}

\author{
Cindy W. Klootwijk, ${ }^{1 *}$ Gertjan Holshof, ${ }^{2}$ Agnes van den Pol-van Dasselaar, ${ }^{2,3}$ Koen L. M. van Helvoort, ${ }^{1}$ \\ Bas Engel, ${ }^{4}$ Imke J. M. de Boer, ${ }^{1}$ and Corina E. van Middelaar ${ }^{1}$ \\ ${ }_{1}^{1}$ Animal Production Systems Group, Wageningen University \& Research Center, $6700 \mathrm{AH}$ Wageningen, the Netherlands \\ ${ }^{2}$ Wageningen Livestock Research, Wageningen University \& Research Center, $6700 \mathrm{AH}$ Wageningen, the Netherlands \\ ${ }^{3}$ Aeres University of Applied Sciences, $8251 \mathrm{JZ}$ Dronten, the Netherlands \\ ${ }^{4}$ Biometris, Wageningen University \& Research Center, 6700 AA Wageningen, the Netherlands
}

\section{ABSTRACT}

The rising plate meter (RPM) is used to measure grass height, which subsequently is used in a calibration equation to estimate herbage mass (HM), an important parameter for optimization of feed management in grazing systems. The RPM is placed on the sward and measures the resistance of the sward toward the plate, which depends not only on grass length, but also on sward structure. The accuracy of the calibration equation for the RPM to estimate HM across grazing systems, however, has not yet been evaluated. Therefore, our aim was to analyze the effect of intensive grazing systems on RPM calibration for perennial ryegrass pastures. To do so, we studied 2 grazing systems: compartmented continuous grazing (CCG) and strip grazing (SG), which differ in key grazing characteristics, such as pre- and post-grazing heights and period of regrowth, that may influence tiller density and vertical flexibility of the sward. The experiment was performed from April until October in 2016 and 2017 with 60 dairy cows, at a fixed stocking rate of 7.5 cows per hectare. To calibrate the RPM, 256 direct measurements of $\mathrm{HM}>4 \mathrm{~cm}$ (i.e., above stubble) were collected by cutting and weighing plots of grass for CCG and SG. Our main interest was in the HM above stubble because this is consumed by cows. Herbage mass $<4 \mathrm{~cm}$ represents the stubble left after grazing. Differences in $\mathrm{HM}<4 \mathrm{~cm}$ may (partially) explain differences in HM $>4 \mathrm{~cm}$ between the grazing systems. Therefore, HM $<4 \mathrm{~cm}$ was additionally measured on 4 out of every 8 plots per grazing system by cutting out quadrats to 0 $\mathrm{cm}$ with an electric grass trimmer. Our results showed an average error margin in our calibration equations of 25 to $31 \%$, expressed as the root mean square error of prediction (RMSEP) as a percentage of the observed

Received December 7, 2018.

Accepted June 20, 2019.

*Corresponding author: cindy.klootwijk@wur.nl
$\mathrm{HM}>4 \mathrm{~cm}$. Differences between grazing systems were relatively small, and including grazing system as a factor in the regression model to explain the increase in HM per centimeter of grass did not reduce the RMSEP of the model to any relevant extent. On the other hand, $\mathrm{HM}<4 \mathrm{~cm}$ was significantly greater on CCG compared with SG, with 2,042 $\mathrm{kg}$ of DM per hectare for CCG and $1,676 \mathrm{~kg}$ of DM per hectare for SG. The $\mathrm{HM}<4 \mathrm{~cm}$, however, is not used for grazing, and this difference was not reflected in the $\mathrm{HM}>4 \mathrm{~cm}$. Our results indicate that we can use one region-specific calibration equation for perennial ryegrass pastures across intensive grazing systems, despite relatively large differences in pre- and post-grazing heights and period of regrowth.

Key words: intensive grazing, herbage mass, forage management, rising plate meter

\section{INTRODUCTION}

Several studies have shown that the economic benefit of grazing increases with an increase in grass intake (Evers et al., 2008; Van den Pol-van Dasselaar et al., 2014). Increased grass intake results in decreased feed supplementation, leading to lower feeding costs (Sanderson et al., 2001). Fresh grass intake is, to a large extent, determined by available herbage mass (HM). Accurate measurement of $\mathrm{HM}$, therefore, is of utmost importance for a dairy farmer to optimize feed management. Sanderson et al. (2001), for example, concluded that measuring HM within a $10 \%$ error margin can improve forage budgeting by allocating an adequate amount of grass to the herd. They found this breakeven point by varying the percentage of under- or overestimation of forage yield in the dairy forage system model DAFOSYM (Rotz et al., 1989). Accurately quantifying HM can increase grazing efficiency and, thereby, the economic benefit of grazing (Holshof et al., 2015; McSweeney et al., 2015). Allocating an adequate amount of grass to the herd may increase grazing efficiency and reduce variations in DMI and, hence, fluctuations in 
milk production (Hennessy et al., 2015). To date, however, a considerable number of farmers still base grazing management decisions on intuitive decisions and visual assessments of standing biomass (McSweeney et al., 2015).

Cutting and weighing grass is a direct and accurate method to estimate HM, but it is also a time-intensive and destructive method and, therefore, is not always used in practice. Currently several tools are available to estimate HM in a nondestructive way. A common, nondestructive, and easy-to-use tool is the rising plate meter (RPM), which measures grass height to estimate HM (Sanderson et al., 2001). The RPM is placed on the sward and measures the resistance of the sward toward the plate, which depends not only on grass length but also on sward structure ('t Mannetje, 2000; Fehmi and Stevens, 2009). Grass height is translated into HM in kilograms of DM per hectare using a calibration equation that includes a factor to represent the linear relationship between grass height and biomass based on cutting and weighing. Rising plate meter readings can be incorporated into grassland management programs such as PastureBase Ireland and Grip op Gras (Stienezen et al., 2018), which can assist in choosing which paddocks to use for grazing and which for cutting, as well as determining the optimal timing of these activities.

For most RPM, a standard calibration equation is provided by the manufacturer. When estimating HM with the RPM, however, it is important to use contextspecific calibration equations, as standard calibration equations may under- or overestimate HM in practice. In the United States, for example, Sanderson et al. (2001) found an error rate of $26 \%$ in comparing estimated HM, calculated via a universal RPM equation developed in New Zealand, with measured (i.e., cutting and weighing) HM in pastures in Pennsylvania, Maryland, and West Virginia. Key factors that affect the relationship between RPM and HM are tiller density and vertical flexibility of the sward, which differ across climate, season, grass variety, and soil type (Fehmi and Stevens, 2009; Ferraro et al., 2012; Nakagami and Itano, 2013).

Because the grazing system also affects tiller density and vertical flexibility of the grass, we hypothesize that grazing systems might also influence the relationship between RPM and HM (Fehmi and Stevens, 2009; Nakagami and Itano, 2013). To the authors' knowledge, these effects of grazing system have not been studied so far. Therefore, our aim was to analyze the effects of grazing system on RPM calibration for HM.

To do this, we studied 2 grazing systems: compartmented continuous grazing $(\mathbf{C C G})$ and strip grazing
(SG), which differ in key grazing characteristics, such as pre- and post-grazing sward heights and period of regrowth, that may influence tiller density and vertical flexibility of the sward. Both CCG and SG are examples of daily rotational grazing systems suitable for intensive Dutch dairy farms with feed supplementation (Holshof et al., 2018). Particularly in intensive grazing systems, accurate HM estimates are critical for feed budgeting, as the balance between fresh grass allowance and feed supplementation needs to be correct.

\section{MATERIALS AND METHODS}

\section{Experimental Design}

Our grazing experiment was performed at the Dairy Campus research facility in Leeuwarden, the Netherlands, during the grazing seasons of 2016 and 2017. Sixty dairy cows were allocated to 2 grazing systems (CCG or $\mathrm{SG}$ ) in 2 replications. Cows were equally stratified based on parity, days in milk, milk constituent yield, and fat- and protein-corrected milk yield, to ensure balanced distribution of the cows. Cows were randomly allocated to 4 treatment groups of 15 each, resulting in a randomized complete design. Cows had an average lactation number of $2.5 \pm 1.2( \pm \mathrm{SD} ; 16$ primiparous and 44 multiparous) in 2016 and $2.6 \pm$ 1.4 (12 primiparous and 48 multiparous) in 2017. Body weight was, on average, $582 \pm 67 \mathrm{~kg}$ in 2016 and $617 \pm$ $73 \mathrm{~kg}$ in 2017.

All cows calved from December to March, before the grazing season. In total we used 8 ha of grassland, implying a fixed stocking rate of 7.5 cows per hectare of grazing area (classified as intensive grazing). Standard grazing time was from 0830 to $1600 \mathrm{~h}$. Cows had access to the pasture between morning and afternoon milkings and were housed indoors in a cubicle barn the rest of the time, where they were supplemented with roughage and concentrates. The botanical composition of the fields was $72 \%$ perennial ryegrass (Lolium perenne L.), $12 \%$ timothy grass (Phleum pratense L.), 11\% rough meadow grass (Poa trivialis L.), and $5 \%$ other species.

Both CCG and SG are rotational grazing systems in which cows receive a new grazing area daily. These systems, however, largely differ in pre- and post-grazing heights and period of regrowth, important factors in characterizing grazing systems. The CCG system has been introduced in the Netherlands recently, to balance grassland utilization and labor intensity (Holshof et al., 2018). The available grazing area in a CCG system is divided into blocks for continuous grazing, where each block is subdivided into compartments of fixed size, with a different compartment grazed each 


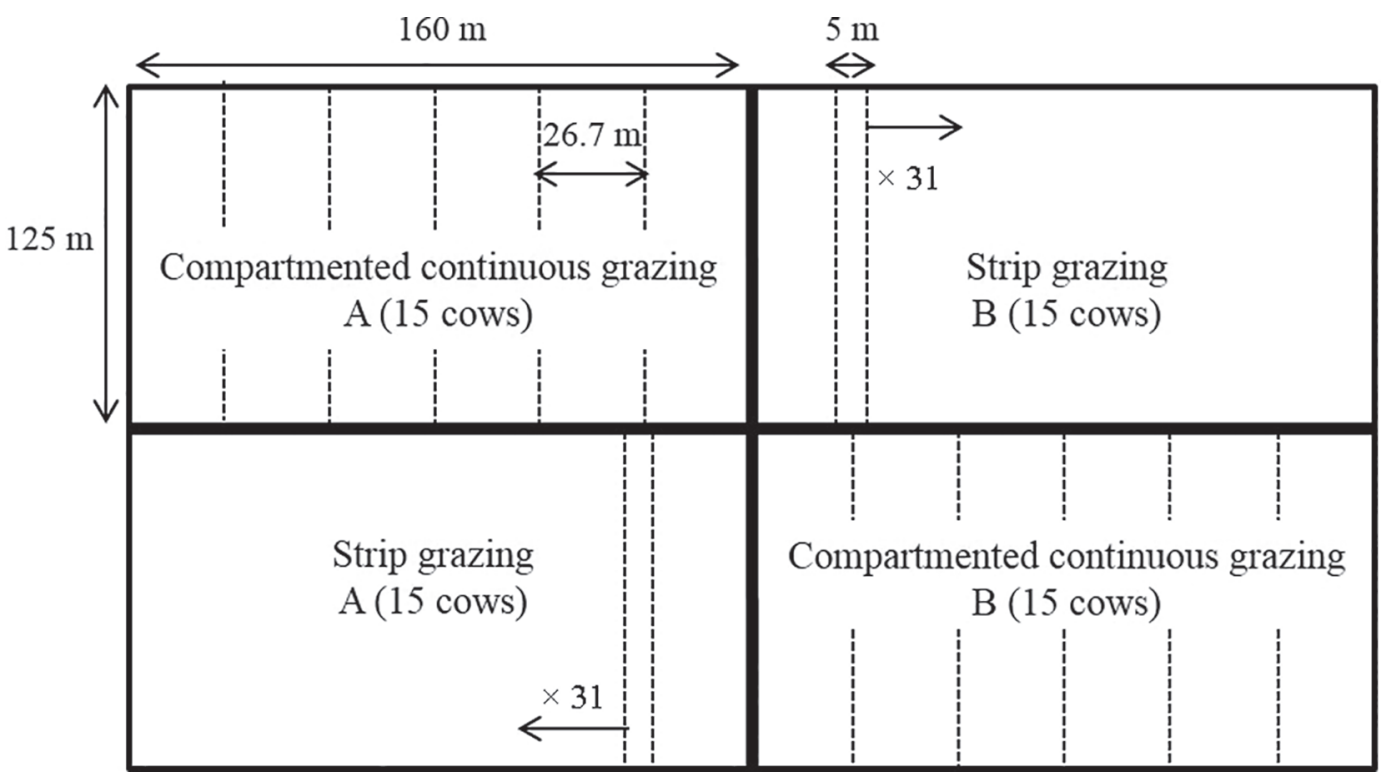

Figure 1. Overview of the grazing experiment with 2 grazing systems - compartmented continuous grazing (CCG) and strip grazing (SG) in 2 replicates (A and B). Both CCG and SG are rotational grazing systems in which cows receive a new grazing area daily. In our experiment, cows rotated across 6 compartments in the CCG system and across 31 strips in the SG system.

day. Each CCG replicate was 2 ha and was divided into six 0.33-ha compartments (Figure 1). On a grazing day, therefore, each cow had access to $222 \mathrm{~m}^{2}$ fresh grass allowance. Each compartment was grazed 30 times. Each SG replicate was 2 ha and was divided into 31 0.07-ha strips. On a grazing day, each cow had access to $43 \mathrm{~m}^{2}$ fresh grass allowance and the strip of the previous day, to provide more space to walk (in total $86 \mathrm{~m}^{2}$ ). Each strip was grazed 6 times.

For CCG, 5 compartments were grazed, and the sixth was cut for silage, to remove rejected patches. After regrowth (on average $10 \mathrm{~d}$ ) the sixth compartment was added to the rotation to provide fresh grass for grazing, and the next compartment was selected to produce grass for silage. So the cows spent 1 day in each compartment and rotated around the compartments available for grazing over a 5-d period. Period of regrowth (i.e., days before cows returned to the same compartment), therefore, was $4 \mathrm{~d}$ for CCG. For SG, blocks of 4 strips were cut for silage and to remove rejected patches after 2 grazing events. After regrowth, the cut strips were again added to the rotation. The period of regrowth was, on average, $20 \mathrm{~d}$ for SG.

The period of regrowth influenced the fresh grass allowance in CCG and SG, depending on the grass growth (influenced by weather conditions, see Appendix Table A1). Fresh grass allowance was measured by performing weekly grass height measurements in all compartments and strips. Per compartment or cluster of strips, about 60 measurements were performed, walking in a $\mathrm{W}$-shape through the compartments and strips. The Jenquip EC10 (NZ Agriworks Ltd., Feilding, New Zealand; diameter $36 \mathrm{~cm}$, average pressure $0.47 \mathrm{~g}$ per square centimeter) was used for grass height measurements in this study. The same RPM was also used for developing the Dutch standard equation for estimating HM of perennial ryegrass pastures (Holshof and Stienezen, 2016). The EC10 measures the grass height in clicks, with each click representing $0.5 \mathrm{~cm}$ (DairyNZ, 2008).

Based on the fresh grass allowance, the amount of roughage supplementation was adjusted to provide sufficient feed for cows on pasture. Total DMI was set at $21 \mathrm{~kg}$ of DM per cow per day, and the concentrate allowance was fixed at $5.4 \mathrm{~kg}$ of DM per cow per day. Roughage supplementation was at least $5.0 \mathrm{~kg}$ of DM per cow per day, with a maximum of $8.0 \mathrm{~kg}$ of maize silage supplemented with grass silage according to requirements. In addition to the adaptation in supplementary feeding, daily grazing time was reduced by $2 \mathrm{~h}$ when total grass height was below $60 \mathrm{~mm}$ for CCG, to ensure sufficient grass growth for the next grazing. For $\mathrm{SG}$, to match daily grazing time with grass allowance, grazing time was reduced by $2 \mathrm{~h}$ when fresh grass allowance was below $4.0 \mathrm{~kg}$ of DM per cow per day.

\section{Calibration Measurements}

To calibrate the RPM, we conducted direct measurements on HM by cutting and weighing plots of grass for 
CCG and SG. Similar to the methodology of Kennedy et al. (2007), as will be described in this section, we sampled plots with an average size of $12 \mathrm{~m}^{2}$. For each plot, grass height was measured just before and after cutting, and HM was (directly) determined by weighing. In total there were 8 measurement days in 2016 (May 12, May 19, Jun. 9, Jul. 7, Jul. 14, Aug. 9, Sep. 8, Sep. 15) and 8 measurements days in 2017 (May 9, May 17, Jun. 8, Jun. 13, Jul. 11, Jul. 14, Aug. 8, Aug. 11). On each measuring day, 16 plots were cut in fields A or B (Figure 1), with 8 plots per grazing system. For each grazing system, 4 plots with relatively high and 4 plots with relatively low grass heights were cut, to maximize the range of grass height, which yields more accurate estimates in the regression calculations that will follow. The cutting height was set at $4 \mathrm{~cm}$ to simulate the stubble remaining after grazing (Kennedy et al., 2007). Herbage mass $>4 \mathrm{~cm}$, therefore, was assumed to represent HM for grazing.

Within each of the 16 plots, we conducted 10 grass height measurements before cutting and 10 after. Using these data, we calculated the average grass height above stubble per plot by subtracting the average grass height after cutting from the average grass height before cutting. This average grass height $>4 \mathrm{~cm}$ was related to $\mathrm{HM}>4 \mathrm{~cm}$ per plot and subsequently expressed per hectare. We did this in order to determine whether a region-specific calibration equation is accurate across grazing systems above the stubble, because stubble is not grazed.

Herbage mass $>4 \mathrm{~cm}$ was quantified by cutting plots with a Haldrup grass harvester (Haldrup Field Research, Ilshofen, Germany; cutting table width 1,510 $\mathrm{mm}$ ), a method also described by 't Mannetje (2000). The precise length of the plots was measured with a measuring tape. The Haldrup harvester automatically collects and weighs the harvested grass per plot. After weighing, a grass sample of about $1 \mathrm{~kg}$ was taken with a sample drilling cylinder. Grass samples were analyzed for DM content by drying in a forced-air oven (UF1060 plus, Memmert GmbH and Co. KG, Schwabach, Germany) at $105^{\circ} \mathrm{C}$ for $24 \mathrm{~h}$.

Differences in $\mathrm{HM}<4 \mathrm{~cm}$ may (partially) explain differences in $\mathrm{HM}>4 \mathrm{~cm}$ between both grazing systems. Additional measurements were conducted, therefore, on 4 out of each 8 plots per grazing system, to quantify $\mathrm{HM}<4 \mathrm{~cm}$. Herbage mass $<4 \mathrm{~cm}$ was quantified per plot by clipping one $0.09-\mathrm{m}^{2}$ quadrat to bare ground $(0 \mathrm{~cm})$ with an electric grass trimmer (HSA 25; Andreas Stihl Ag and Co. KG, Waiblingen, Germany) and scissors. The quadrats were marked with a steel frame of 30 by $30 \mathrm{~cm}$. All HM in the quadrat was carefully collected, weighed, and analyzed for DM content by drying.

\section{Statistical Analyses}

We used linear regression to estimate HM based on grass height measurements with the RPM (i.e., build calibration equations). The sampled and cut plots served as the experimental units in this analysis. The average grass height per plot was the explanatory variable (x-variable), denoted by $\mathrm{H}$ and expressed in $\mathrm{cm}$. The response variable (y-variable) was HM, denoted by $\mathrm{y}$ and expressed in kilograms of DM per hectare. Our first interest was the effect of grazing system on the relationship between HM and average grass height, so the model comprises effects for grazing system, making the intercept and slope (of height $\mathrm{H}$ ) dependent on the grazing system. In addition, seasonal effects were added, because existing literature shows effects of month and year on the relationship between HM and grass height (Ferraro et al., 2012; Nakagami and Itano, 2013). To that end, the 8 measurement days per year were classified into months: May, June, July, August, and September for 2016, and May, June, July, and August for 2017.

Interactions between explanatory variable $\mathrm{H}$ and experimental factors for grazing system, month, and year were limited to 2-factor interactions. This regression model will be referred to as the full model. Ideally, the full model would include year as a random effect, employing a mixed model analysis. This was not feasible, however, because the component of variance associated with year cannot be estimated with acceptable accuracy based on only 2 years' data. Year effects therefore were included as fixed effects. This full model was used as a benchmark to compare with a reduced and more practical model that did not include year effects, to see how much unexplained variation in the reduced model is due to years.

The full model reads as follows (Equation [1]):

$$
\begin{aligned}
y_{i j k l}=\mu+ & S_{i}+M_{j}+Y r_{k}+M Y r_{j k}+\beta H_{i j k l}+\beta_{S, i} H_{i j k l} \\
& +\beta_{M, j} H_{i j k l}+\beta_{Y r, k} H_{i j k l}+\epsilon_{i j k l},
\end{aligned}
$$

where $y_{i j k l}$ is the $\mathrm{HM}>4 \mathrm{~cm}$ of the $l$ th sampled plot of grazing system $i$ in month $j$ of year $k$, and $H_{i j k l}$ is the corresponding average grass height; $S_{i}, M_{j}$, and $Y r_{k}$ are main effects of grazing systems, months, and years, respectively; and $M Y r_{j k}$ are interactions between months and years that affect the intercept; $\beta_{M, j} H_{i j k l}$ represents the interaction between month and height, affecting the slope of height $H$. The random error term $\epsilon_{i j k l}$ was assumed to be independently normally distributed around zero with constant variance $\sigma^{2}$. The so-called cornerstone representation, a common feature of statistical software, was used, implying that, for instance, $\mu$ 
is the mean HM for system SG, in September in year 2, and effects in the intercept, such as $S_{i}$, are relative to this reference combination. Similarly, $\beta$ is the slope of height for SG in September of 2017 and effects in the slope, such as $\beta_{S, i}$ are relative to this reference combination.

We looked at the effects of grazing system on HM $<4 \mathrm{~cm}$, because such effects may (partially) explain differences in $\mathrm{HM}>4 \mathrm{~cm}$. Because height is more or less constant, attention was restricted to a comparison of means by the $t$-test.

To further disentangle the effects of grazing system and season on the relationship between grass height and $\mathrm{HM}>4 \mathrm{~cm}$, we analyzed the effect of year by comparing the full model (Equation [1]) with a reduced model without year effects (Equation [2]). A similar interpretation of effects as in Equation [1] holds for the reduced model, where year effects have been omitted:

$$
\begin{aligned}
y_{i j l}=\mu+ & S_{i}+M_{j}+\beta H_{i j l}+\beta_{S, i} H_{i j l} \\
& +\beta_{M, j} H_{i j l}+\epsilon_{i j l} .
\end{aligned}
$$

We compared the prediction accuracy of our fitted regression equations with the existing Dutch standard equation translated to $\mathrm{HM}>4 \mathrm{~cm}$ (Equation [3]). Holshof and Stienezen (2016) developed this calibration equation for Dutch pasture conditions, based on cutting trials in the Netherlands during the growing seasons of 2014 and 2015. They found the following calibration equation for total HM ( $\mathrm{kg}$ of DM per hectare): $845+$ $210 \times$ grass height $(\mathrm{cm})$. Because the intercept $(845)$ and the grass height up to $4 \mathrm{~cm}$ represent the HM of stubble, we translated the equation for $\mathrm{HM}>4 \mathrm{~cm}$ as follows:

$$
\mathrm{HM}>4 \mathrm{~cm}=210 \times \text { grass height }(\mathrm{cm})>4 \mathrm{~cm} .
$$

The prediction accuracy of the different regression models was expressed in terms of the root mean square error of prediction (RMSEP; Equation [4]):

$$
R M S E P=\sqrt{\frac{1}{n} \sum_{i j k l}\left(\hat{y}_{i j k l}-y_{i j k l}\right)^{2}},
$$

where $y_{i j k l}$ is the observed HM and $\hat{y}_{i j k l}$ the corresponding prediction (fitted value), and $n$ is the total number of plots. Roughly, the prediction error is between plus and minus twice the RMSEP. The RMSEP was determined by leave-one-out cross validation and was calculated from the squared deletion residuals (Montgomery and Peck, 1992).
The statistical program SPSS, Version 22.0 (IBM Corp., Armonk, NY), was used to perform the regression calculations.

\section{RESULTS}

In Figure 2, HM $>4 \mathrm{~cm}$ is plotted against grass height $>4 \mathrm{~cm}$ and expressed per hectare, with one measurement representing one cut plot. We found a positive correlation between grass height $>4 \mathrm{~cm}$ and $\mathrm{HM}>4 \mathrm{~cm}$ for CCG ( $\mathrm{r}=0.785 ; P<0.001)$, SG $(\mathrm{r}=0.911 ; P<$ $0.001)$, and the overall data set $(\mathrm{r}=0.900 ; P<0.001)$. The lines for CCG and SG in Figure 2 represent lines of best fit, with an $\mathrm{R}^{2}$ of 0.62 for CCG and 0.83 for SG. The line of best fit without accounting for grazing system resulted in a $R^{2}$ of 0.81 . Grass height $>4 \mathrm{~cm}$ varied from 0.4 to $14 \mathrm{~cm}$, with an average of $3.1 \pm 0.1 \mathrm{~cm} \mathrm{( \pm}$ SD) for CCG and $5.0 \pm 0.3 \mathrm{~cm}$ for SG. Herbage mass $>4 \mathrm{~cm}$ varied from 62 to $3439 \mathrm{~kg}$ of DM per hectare, with an average of $671 \pm 34 \mathrm{~kg}$ of DM per hectare for CCG and 1,113 $\pm 63 \mathrm{~kg}$ of DM per hectare for SG. The actual height of the grass after cutting was on average $3.9 \pm 0.0 \mathrm{~cm}$. Figure $3(\mathrm{~A}$ and $\mathrm{B})$ shows the ratio between $\mathrm{HM}>4 \mathrm{~cm}$ and grass height $>4 \mathrm{~cm}$ by month for the growing seasons of 2016 and 2017, respectively.

Using the full model, we see that the average increase in HM per centimeter of grass was smaller $(P<0.001$; Table 1) for CCG than for SG (163 vs. $223 \mathrm{~kg}$ of DM per hectare per $\mathrm{cm}$, respectively). Using the reduced model, however, we no longer found evidence of differences in slope across grazing systems. In addition, excluding grazing system from the reduced model did not markedly affect RMSEP. Differences between grazing systems in $\mathrm{HM}>4 \mathrm{~cm}$ were similar at grass heights $<10 \mathrm{~cm}$ (Figure 2).

The HM $<4 \mathrm{~cm}$ varied from $744 \mathrm{~kg}$ of DM per hectare to $3,456 \mathrm{~kg}$ of DM per hectare, with an average of $2042 \pm 70 \mathrm{~kg}$ of DM per hectare for CCG and $1676 \pm$ $77 \mathrm{~kg}$ of DM per hectare for SG (Figure $4 \mathrm{~A}$ and B). The $t$-test showed that the grazing system clearly affected the mean $\mathrm{HM}<4 \mathrm{~cm}(P<0.001)$.

To better understand the effects of grazing system and season on the relationship between grass height and $\mathrm{HM}>4 \mathrm{~cm}$, we analyzed the effect of year by comparing the full model (Equation [1]) with a reduced model without year effects (Equation [2]). Table 1 shows results of the full model with RMSEP of $231 \mathrm{~kg}$ of DM per hectare. By comparing the years 2016 and 2017 , we found that the average intercept was greater $(P<0.001)$ for 2016 than for 2017 (185 vs. $19 \mathrm{~kg}$ of DM per hectare, respectively), whereas the average increase in HM per centimeter was not shown to be affected by 
year $(P=0.273)$. Differences between months were not the same in the 2 years $(P<0.001)$.

The RMSEP of the reduced model excluding year effects increased from 231 to $274 \mathrm{~kg}$ of DM per hectare (Table 1). This leads to an increased prediction error of $\pm 86 \mathrm{~kg}$ of DM per hectare, which is $10 \%$ of the average observed HM $>4 \mathrm{~cm}$ (i.e., $892 \pm 38 \mathrm{~kg}$ of DM per hectare). When plotting the deletion residuals from the reduced model against the deletion residuals from the full model, we found that the increase in prediction accuracy of the full model is mainly attributable to June estimates (Figure 5A and B).

Because the month of June was so influential in the model for $\mathrm{HM}>4 \mathrm{~cm}$ and is generally known to give inaccurate results with the RPM due to the reproductive stage of grass in this month (Michell and Large, 1983), the reduced model without year effects was analyzed again after excluding all June measurements. This model, therefore, cannot be used to translate grass height measurements during the reproductive stage into HM. Table 1 shows the results of this analysis. The RMSEP decreased from 274 to $226 \mathrm{~kg}$ of DM per hectare compared with the reduced model including June measurements. Although the average increase in HM per centimeter of grass showed an interaction with grazing system $(P=0.036)$, excluding grazing system from the model did not affect the RMSEP to any great extent.

To improve the accuracy of estimating HM in restricted rotational grazing systems in the Netherlands, we compared the RMSEP of the full and the reduced model with the standard Dutch calibration equation (Equation [3]). The RMSEP of the full model (231 $\mathrm{kg}$ of DM per hectare) was lower compared with the standard Dutch calibration equation $(271 \mathrm{~kg}$ of DM per hectare). The reduction in RMSEP, however, was mainly observed around June, which was during the reproductive stage for the grass. The RMSEP of the reduced model (274 $\mathrm{kg}$ of DM per hectare), was comparable to the RMSEP of the Dutch calibration equation, suggesting that accounting for month and grazing system does not increase prediction accuracy to a particularly relevant extent. When we excluded June measurements, however, we found an RMSEP of 226

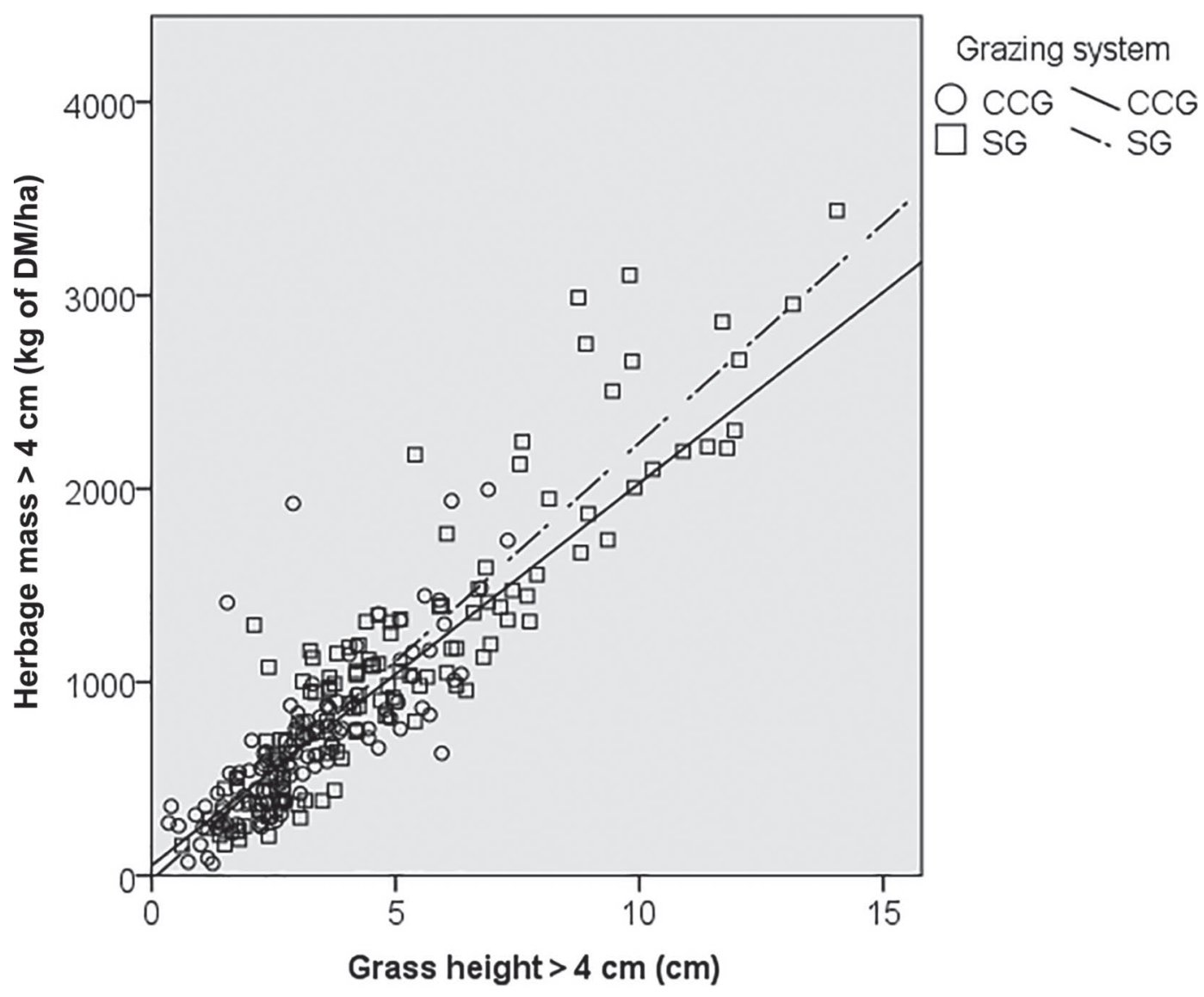

Figure 2. Herbage mass $>4 \mathrm{~cm}$ plotted against grass height $>4 \mathrm{~cm}$ by grazing system [compartmented continuous grazing (CCG, circles) and strip grazing (SG, squares)]. The lines for CCG (solid) and SG (broken) represent lines of best fit with an $\mathrm{R}^{2}$ of 0.62 for CCG and 0.83 for SG. 


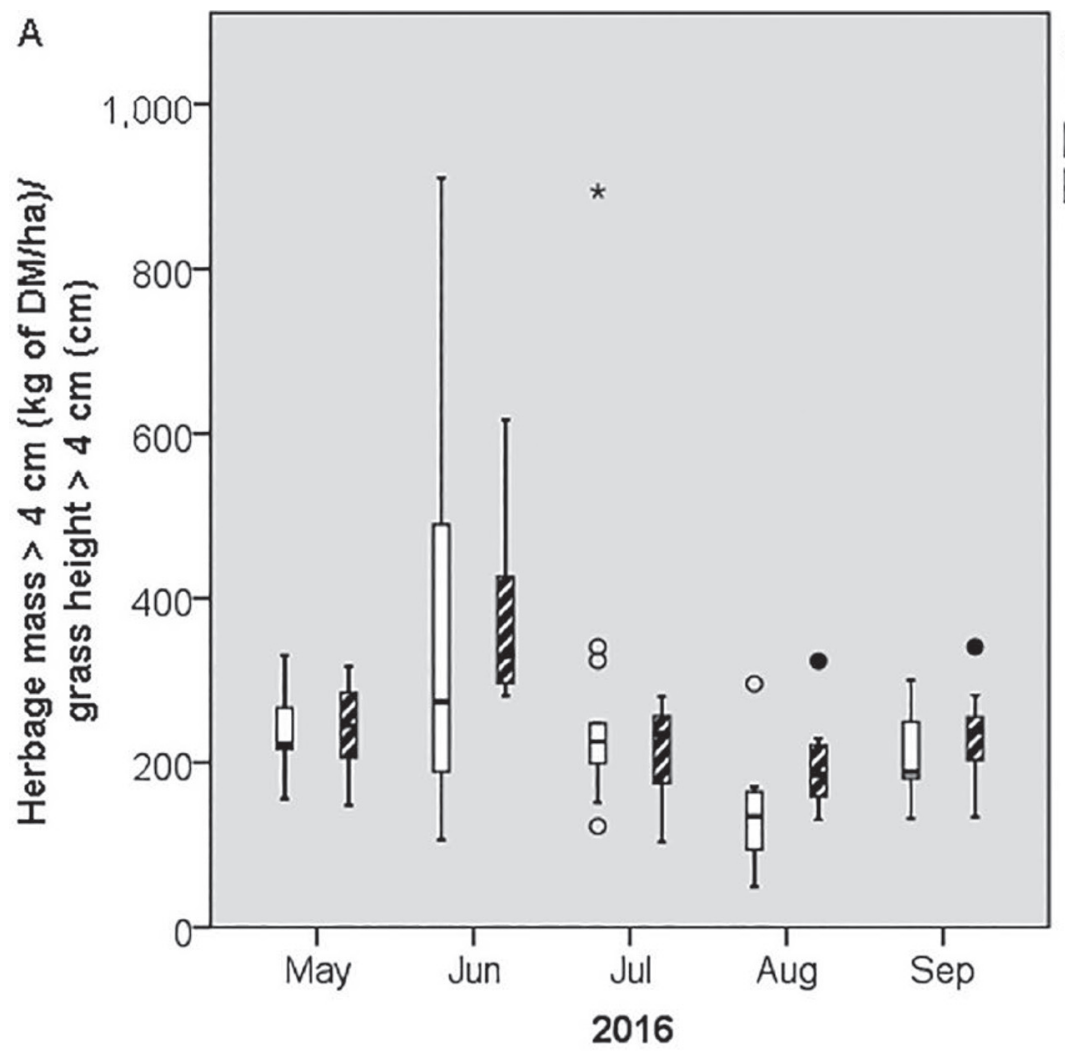

\section{Grazing \\ system \\ $\square \mathrm{CCG}$ \\ $\mathbb{Z S G}$}

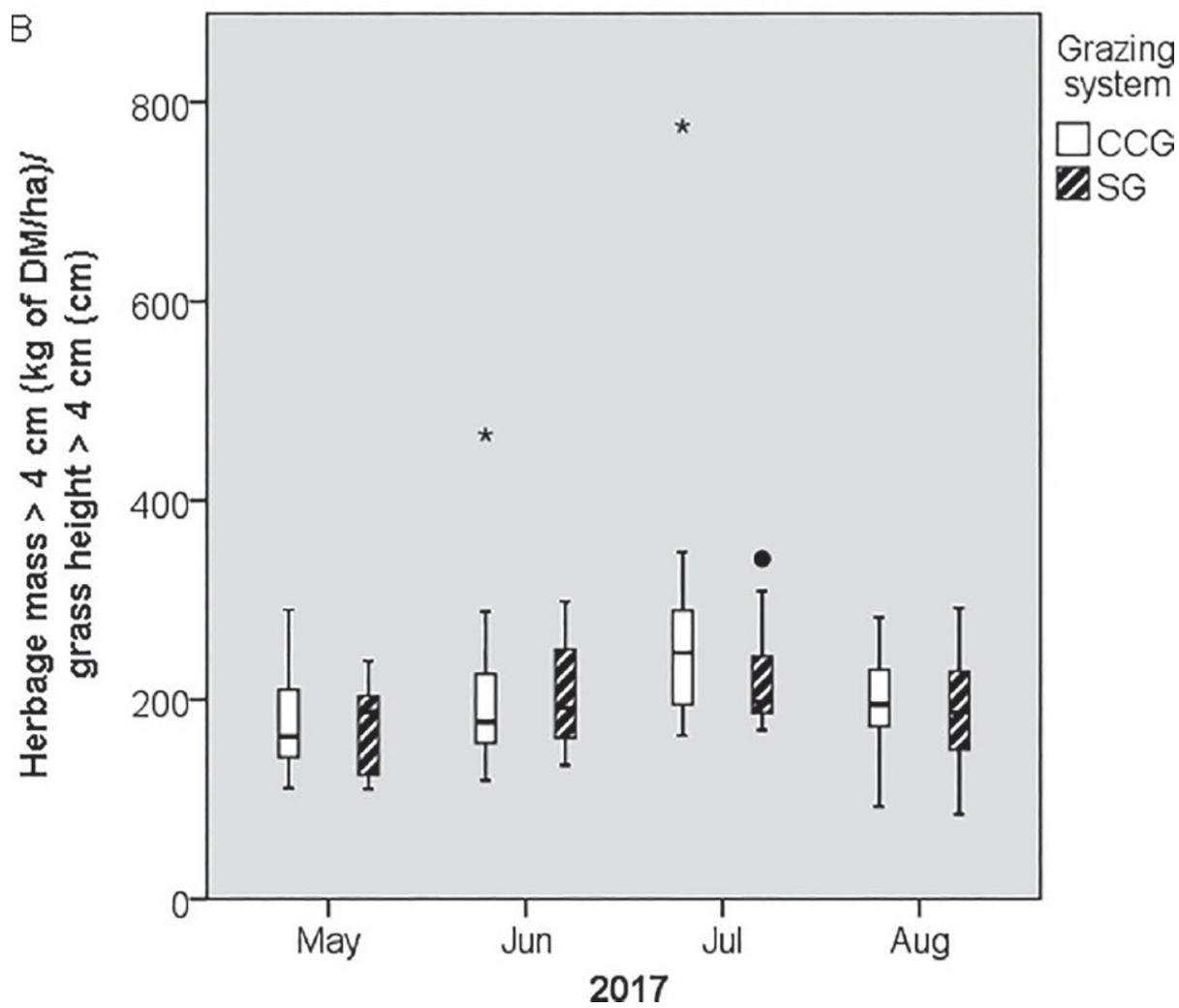

Figure 3. Ratio between herbage mass $>4 \mathrm{~cm}$ and grass height $>4 \mathrm{~cm}$ for compartmented continuous grazing (CCG) and strip grazing (SG) by month for 2016 (A) and 2017 (B). Boxes represent the interquartile ranges (IQR), with lines for the median. The whiskers represent the lowest and highest values. The dots are the outliers (1.5 to 3 times the IQR) and the asterisks are the extremes ( $>3$ times the IQR) 
$\mathrm{kg}$ of DM per hectare with the reduced model, which is lower than the RMSEP of the Dutch calibration equation (271 kg DM per hectare).

\section{DISCUSSION}

Using the full model, we found that the average increase in HM per centimeter of grass was smaller for CCG than for SG. The lower slope for CCG might potentially be explained by a higher leaf proportion and a lower dead material proportion in $\mathrm{HM}>4 \mathrm{~cm}$ compared with SG, due to differences in pre- and postgrazing sward height and period of regrowth. Curran et al. (2010) found a higher leaf proportion for grass both above and below $4 \mathrm{~cm}$ and a lower dead proportion $(>4$ $\mathrm{cm})$ for a low pre-grazing HM (HM $>0 \mathrm{~cm}: 1600 \mathrm{~kg}$ of DM per hectare) compared with a high pre-grazing HM (HM >0 cm: $2400 \mathrm{~kg}$ of DM per hectare), resulting in a lower HM density in kilograms of DM per hectare per centimeter for the low pre-grazing HM. Differences between grazing systems, however, were relatively small, and including grazing system as a factor in the regression model to explain the increase in HM per centimeter of grass did not reduce the RMSEP of the model to any important extent.

In contrast, $\mathrm{HM}<4 \mathrm{~cm}$ was clearly affected by grazing system. The larger $\mathrm{HM}<4 \mathrm{~cm}$ for $\mathrm{CCG}$ might be explained by a higher tiller density for CCG compared with SG. From November 2016 onward, tiller density was indeed higher for CCG than for SG $(P<0.05$; N. J. Hoekstra, Louis Bolk Institute, Bunnik, the Netherlands, personal communication). This finding is in line with literature, showing an increased tiller density at increasing grazing pressure per grazing event, to compensate for a loss in leaf area index (Matthew et al., 1996; Hernández Garay et al., 1999). This difference in $\mathrm{HM}<4 \mathrm{~cm}$ between grazing systems, however, was not expressed in $\mathrm{HM}>4 \mathrm{~cm}$.
By comparing the full model (Equation [1]) with the reduced model (Equation [2]), we found a year effect on the absolute level of HM, but not on the average increase in HM per $\mathrm{cm}$. This suggests that the seasonal pattern may be largely similar for different years, although coefficients are likely to differ to some extent across years. These findings are in line with literature describing year effects (Braga et al., 2009; Ferraro et al., 2012; Nakagami, 2016). Differences between years could easily be explained by differences in weather conditions, because the latter influence the proportion of leaf, stem, and dead material in the sward and, thereby, the density in kilogram of DM per centimeter of grass height (Curran et al., 2010). In principle, for instance, covariates for past weather conditions could be included when working on a monthly basis.

When further analyzing month effects with the full model (Equation [1]), we found a clear seasonal pattern, with a marked decrease in average HM per centimeter of grass height for June compared with May, July, August, and September. This seasonal pattern is in line with findings in literature for cool-season grass swards (Michell and Large, 1983; Ferraro et al., 2012; Nakagami and Itano, 2013). The decrease in slope in June can be explained by the onset of the reproductive stage of perennial ryegrass in the northern hemisphere (Michell and Large, 1983; Nakagami and Itano, 2013). Reproductive tillers contribute to increasing grass height, but without an equivalent increase in HM, because the density of such tillers is low. Compared with vegetative tillers, reproductive tillers contain a larger proportion of stem and dead material, which is generally heavier and contains a higher percent of DM and a smaller proportion of leaf material (Curran et al., 2010). Indeed, we observed an increase in tall rejected grass in the flowering stage in June, especially in the CCG system in 2016. In line with these findings, we found a positive correlation between percent of DM and

Table 1. $P$-values and root mean square error of prediction (RMSEP) for full regression model of grass height $(>4 \mathrm{~cm})$ versus herbage mass (kilograms of DM per hectare), with year effects, reduced regression model without year effects, and reduced regression model without year effects and excluding June measurements

\begin{tabular}{lccc}
\hline Item & $\begin{array}{c}\text { Full } \\
\text { model }\end{array}$ & $\begin{array}{c}\text { Reduced } \\
\text { model }\end{array}$ & $\begin{array}{c}\text { Reduced model } \\
\text { without June }\end{array}$ \\
\hline $\begin{array}{l}P \text {-values } \\
\text { Grazing system }\end{array}$ & 0.005 & 0.141 & 0.055 \\
Year & $<0.001$ & & 0.586 \\
Month & $<0.001$ & 0.351 & $<0.001$ \\
Year $\times$ Month & $<0.001$ & & 0.036 \\
Grass height $>4 \mathrm{~cm}$ & $<0.001$ & $<0.001$ & 0.707 \\
Grazing system $\times$ Grass height $>4 \mathrm{~cm}$ & $<0.001$ & 0.059 & 226 \\
Year $\times$ Grass height $>4 \mathrm{~cm}$ & 0.273 & 0.877 & \\
Month $\times$ Grass height $>4 \mathrm{~cm}$ & 0.018 & 274 & \\
RMSEP & 231 & & \\
\hline
\end{tabular}



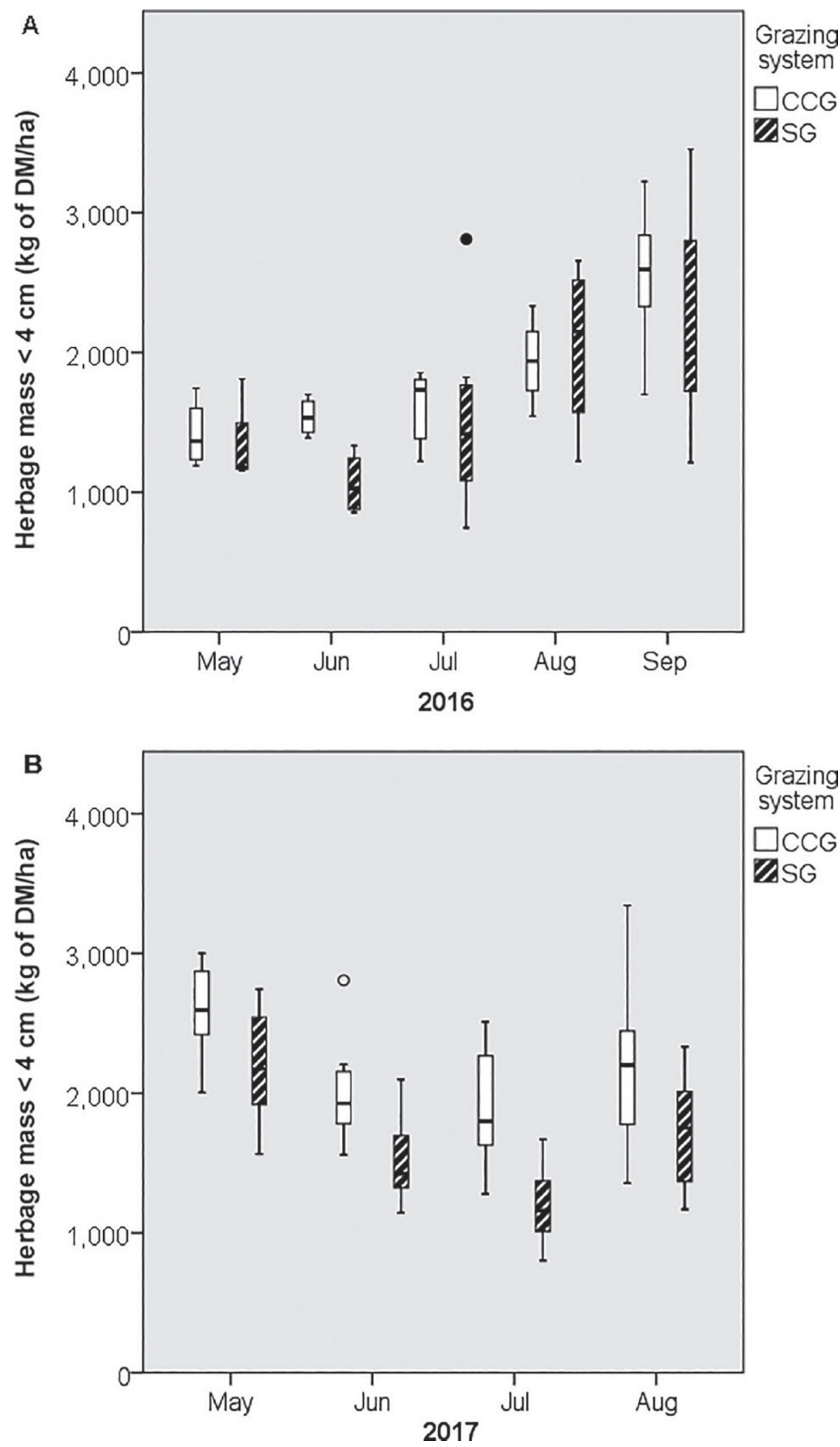

Figure 4. Herbage mass $<4 \mathrm{~cm}$ for compartmented continuous grazing (CCG) and strip grazing (SG) by month for 2016 (A) and 2017 (B). Boxes represent the interquartile ranges (IQR), with lines for the median. The whiskers represent the lowest and highest values. The dots are the outliers (1.5 to 3 times the IQR) and the asterisks are the extremes ( $>3$ times the IQR). 

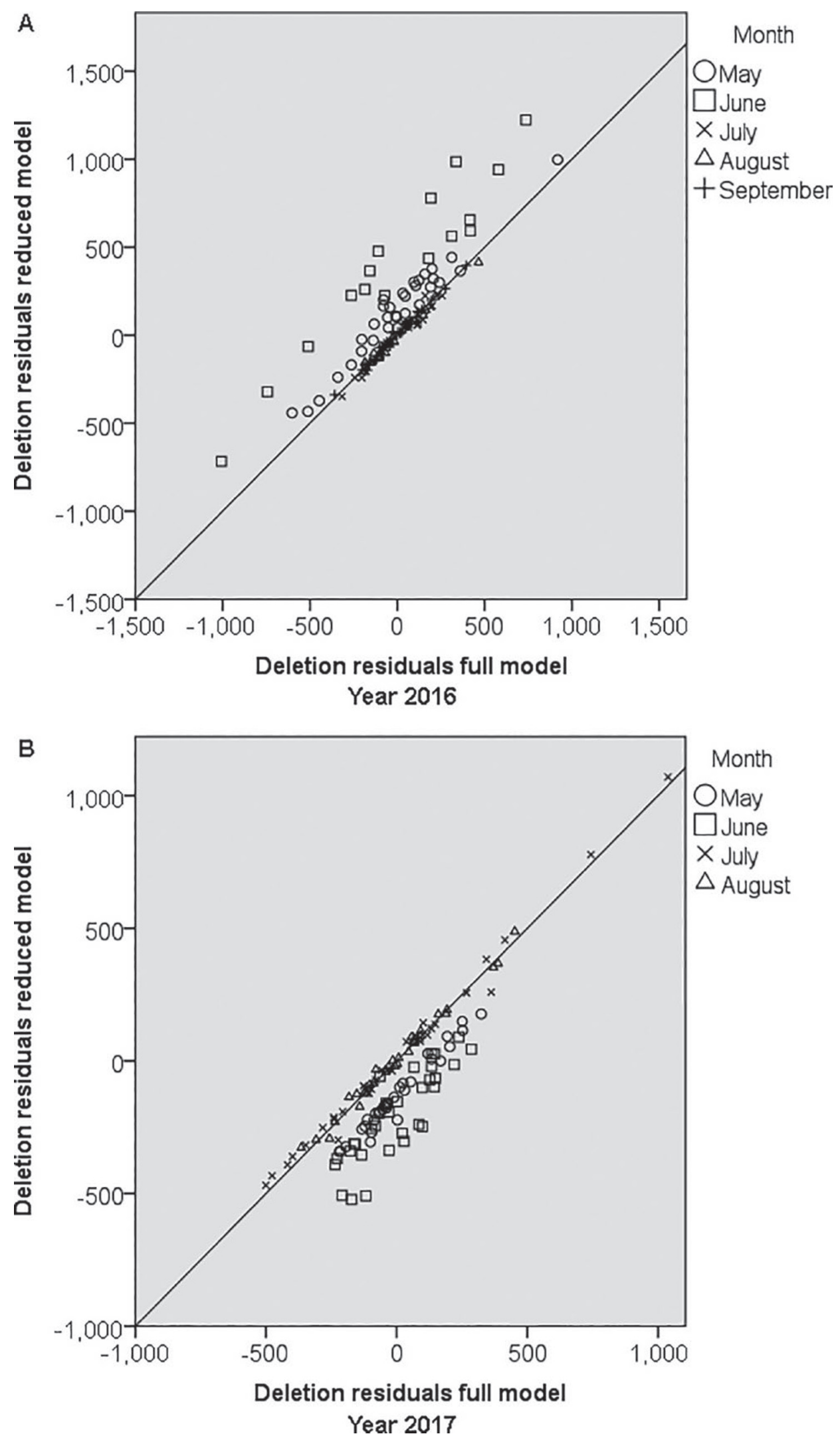

Figure 5. Deletion residuals of the reduced model with year effects plotted against the full model by month for 2016 (A) and 2017 (B). Data are presented in kilograms of DM per hectare. The diagonal line in this figure represents the reference line $\mathrm{y}=\mathrm{x}$. 
intercept $(\mathrm{r}=0.642 ; P=0.004)$ and a negative correlation between percent of $\mathrm{DM}$ and slope $(\mathrm{r}=-0.556$; $P=0.017)$. Dry matter content was greatest in June 2016, for both CCG (23\%) and SG $(19.2 \%)$.

We observed during May that the whole field was equally grazed, resulting in a relatively low abundance of rejected patches. In line with perennial ryegrass, however, timothy grass was more often rejected by the cows in June. Compared with perennial ryegrass, timothy grass might even be stiffer and is expected to result in equal or greater resistance to the plate meter, especially in June. This might also contribute to the decrease in slope of the calibration equation in June. Rough meadow grass, on the other hand, bends easily and is expected to result in equal or lower resistance to the plate meter. With the grass species being equally distributed in the field, we do not expect an effect of the botanical composition on the relationship between grass height $>4 \mathrm{~cm}$ and $\mathrm{HM}>4 \mathrm{~cm}$. This study can serve as a valuable guide for other researchers to investigate the forage mass estimations of different forage species in different regions of the world.

Our comparison of calibration equations showed that the (modified) Dutch standard equation (Equation [3]) is suitable to estimate HM $>4 \mathrm{~cm}$ in CCG and SG, considering both accuracy and feasibility. Including grazing system in the model did not result in a higher prediction accuracy compared with the Dutch calibration equation. Because these systems largely differ in pre- and post-grazing heights, our results indicate that a region-specific calibration equation is accurate across grazing systems. Overall, however, the calibration equations analyzed in this study showed an average error margin of 25 to $31 \%$, expressing the RMSEP as a percentage of the observed $\mathrm{HM}>4 \mathrm{~cm}$. This exceeds the $10 \%$ that Sanderson et al. (2001) proposed as a maximum error margin for estimating fresh grass availability to increase economic benefits of improved forage budgeting. To obtain higher prediction accuracy with the Dutch calibration equation, we suggest including random year effects in the model, with data based on a long-term study, and excluding measurements of tall rejected grass during the reproductive stage.

\section{CONCLUSIONS}

The HM $<4 \mathrm{~cm}$ was significantly greater for CCG compared with SG, with $2,042 \mathrm{~kg}$ of DM per hectare for CCG and $1676 \mathrm{~kg}$ of DM per hectare for SG. The $\mathrm{HM}<4 \mathrm{~cm}$, however, is not used for grazing, and this difference was not reflected in the $\mathrm{HM}>4 \mathrm{~cm}$. Our results indicate that we can use one region-specific calibration equation for perennial ryegrass pastures across intensive grazing systems, despite relatively large dif- ferences in pre- and post-grazing heights and period of regrowth. The average error margin of our calibration equations, however, was 25 to $31 \%$, expressed as the RMSEP as a percentage of the observed HM $>4 \mathrm{~cm}$. To obtain more reliable results with the Dutch calibration equation, we suggest including random year effects in the model, with data based on a long-term study, and excluding measurements of tall rejected grass during the reproductive stage.

\section{ACKNOWLEDGMENTS}

This work is part of a research program financed by the Province of Fryslân (Leeuwarden, the Netherlands). In addition, this work was carried out within the framework of the Amazing Grazing project (www .amazinggrazing.eu), which is financed by ZuivelNL (Den Haag, the Netherlands), LTO, NZO, and the Dutch Ministry of Agriculture, Nature and Food Quality. We thank the financers of this research and the employees at Dairy Campus for their assistance during field work.

\section{REFERENCES}

Braga, G. J., C. G. S. Pedreira, V. R. Herling, P. H. C. Luz, W. A. Marchesin, and F. B. Macedo. 2009. Quantifying herbage mass on rotationally stocked palisadegrass pastures using indirect methods. Sci. Agric. 66:127-131. https://doi.org/10.1590/S0103 $-90162009000100018$

Curran, J., L. Delaby, E. Kennedy, J. P. Murphy, T. M. Boland, and M. O'Donovan. 2010. Sward characteristics, grass dry matter intake and milk production performance are affected by pre-grazing herbage mass and pasture allowance. Livest. Sci. 127:144-154. https://doi.org/10.1016/j.livsci.2009.09.004.

DairyNZ. 2008. Using the rising plate meter (RPM). DairyNZ farmfact 1-15. DairyNZ, Hamilton, New Zealand.

Evers, A. G., M. H. A. De Haan, A. Van den Pol-van Dasselaar, and A. P. Philipsen. 2008. Weiden onder moeilijke omstandigheden: Een studie naar inkomensverschillen tussen weiden en opstallen [Grazing under difficult circumstances: A study on differences in income between grazing and non-grazing systems]. Report 147. Wageningen UR Animal Sciences Group, Lelystad, the Netherlands.

Fehmi, J. S., and J. M. Stevens. 2009. A plate meter inadequately estimated herbage mass in a semi-arid grassland. Grass Forage Sci. 64:322-327. https://doi.org/10.1111/j.1365-2494.2009.00694.x.

Ferraro, F. P., R. L. G. Nave, R. M. Sulc, and D. J. Barker. 2012 Seasonal variation in the rising plate meter calibration for forage mass. Agron. J. 104:1-6. https://doi.org/10.2134/agronj2011 0190 .

Hennessy, D., L. Delaby, A. Van den Pol-Dasselaar, and L. Shalloo. 2015. Possibilities and constraints for grazing in high output dairy systems. Pages 151-162 in Proc. Grassland Science in Europe 20. NVWV, Wageningen, the Netherlands.

Hernández Garay, A., C. Matthew, and J. Hodgson. 1999. Tiller size density compensation in perennial ryegrass miniature swards subject to differing defoliation heights and a proposed productivity index. Grass Forage Sci. 54:347-356. https://doi.org/10.1046/j 1365-2494.1999.00187.x.

Holshof, G., A. G. Evers, M. H. A. De Haan, and P. G. Galama. 2015. Grazing and difficult circumstances: Economic benefits depend on milk price and grazing efficiency. Pages 236-238 in Proc. Grassland Science in Europe 20. NVWV, Wageningen, the Netherlands. 
Holshof, G., and M. W. J. Stienezen. 2016. Grasgroei meten met de grashoogtemeter. Wageningen University \& Research, Livestock Research, Report 925. Wageningen, the Netherlands.

Holshof, G., R. L. G. Zom, A. P. Philipsen, A. Van Den Pol-Van Dasselaar, and C. W. Klootwijk. 2018. Amazing grazing: Substantial fresh grass intake in restricted grazing systems with high stocking rates. Pages 234-236 in Proc. Grassland Science in Europe 23. Teagasc, Cork, Ireland.

Kennedy, E., M. O'Donovan, J. P. Murphy, L. Delaby, and F. P. O'Mara. 2007. Effect of spring grazing date and stocking rate on sward characteristics and dairy cow production during midlactation. J. Dairy Sci. 90:2035-2046. https://doi.org/10.3168/jds.2006 -368 .

Matthew, C., A. Hernández-Garay, and J. Hodgson. 1996. Making sense of the link between tiller density and pasture production. Pages 83-87 in Proc. New Zealand Grassland Association 57, Waitangi, New Zealand.

McSweeney, D., C. Foley, P. Halton, and B. O'Brien. 2015. Calibration of an automated grass height measurement tool equipped with global positioning system to enhance the precision of grass measurement in pasture-based farming systems. Pages 265-267 in Proc. Grassland Science in Europe 20. NVWV, Wageningen, the Netherlands.

Michell, P., and R. V. Large. 1983. The estimation of herbage mass of perennial ryegrass swards: A comparative evaluation of a risingplate meter and a single-probe capacitance meter calibrated at and above ground level. Grass Forage Sci. 38:295-299. https://doi.org/ 10.1111/j.1365-2494.1983.tb01652.x.
Montgomery, D. G., and E. Peck. 1992. Introduction to Linear Regression Analysis. 2nd ed. John Wiley, New York, NY.

Nakagami, K. 2016. Effects of sites and years on the coefficients of rising plate meter calibration under varying coefficient models. Grassl. Sci. 62:128-132. https://doi.org/10.1111/grs.12117.

Nakagami, K., and S. Itano. 2013. Improving pooled calibration of a rising-plate meter for estimating herbage mass over a season in cool-season grass pasture. Grass Forage Sci. 69:717-723. https:// doi.org/10.1111/gfs.12070.

Rotz, C. A., D. Buckmaster, D. Mertens, and R. Black. 1989. DAFOSYM: A dairy forage system model for evaluating alternatives in forage conservation. J. Dairy Sci. 72:3050-3063.

Sanderson, M. A., C. A. Rotz, S. W. Fultz, and E. B. Rayburn. 2001. Estimating forage mass with a commercial capacitance meter, rising plate meter, and pasture ruler. Agron. J. 93:1281-1286. https: //doi.org/10.2134/agronj2001.1281.

Stienezen, M. W. J., A. P. Philipsen, R. L. M. Schils, and A. Van den Pol-van Dasselaar. 2018. Amazing grazing: Feed wedge and cutting window for grazing systems with high levels of supplementation. Pages 819-821 in Proc. Grassland Science in Europe 23. Teagasc, Cork, Ireland.

't Mannetje, L. 2000. Measuring biomass of grassland vegetation. Pages 151-178 in Field and Laboratory Methods for Grassland and Animal Production Research. L. 't Mannetje and R. M. Jones, ed. CABI publishing, Wallingford, UK.

Van den Pol-van Dasselaar, A., A. P. Philipsen, and M. H. A. De Haan. 2014. Economics of grazing. Pages 662-664 in Proc. Grassland Science in Europe 19. IBERS, Aberystwyth, Wales.

\section{APPENDIX}

Table A1. Average temperature and cumulative rainfall surplus (rainfall minus evaporation) per month for 2016 and 2017

\begin{tabular}{|c|c|c|c|c|c|c|c|c|c|c|c|c|c|}
\hline Item & Year & \multicolumn{12}{|c|}{ Month } \\
\hline$\left({ }^{\circ} \mathrm{C}\right)$ & 2017 & 1.6 & 4.1 & 7.5 & 7.8 & 13.6 & 16.5 & 17.1 & 16.8 & 13.8 & 13 & 7.2 & 4.6 \\
\hline Cumulative rainfall & 2016 & 30 & 93 & 125 & 120 & 78 & 37 & 46 & 33 & 10 & -3 & 48 & 85 \\
\hline surplus (mm) & 2017 & 26 & 52 & 104 & 74 & 25 & -29 & -40 & -46 & 25 & 75 & 121 & 193 \\
\hline
\end{tabular}

